\title{
Unusual ring transformation of $N$-hydroxy-3,5-dinitro-4-pyridone Affording a polyfunctionalized pyrrole
}

\author{
Nagatoshi Nishiwaki,* Kazuo Matsushima, Mina Tamura, \\ Noriko Asaka, Kazushige Hori, Yasuo Tohda, and Masahiro Ariga* \\ Department of Chemistry, Osaka Kyoiku University, \\ Asahigaoka 4-698-1, Kashiwara, Osaka 582-8582, Japan \\ E-mail: nishi@cc.osaka-kyoiku.ac.jp
}

(received 14 Jul 2002; accepted 30 Sep 2002; published on the web 08 Oct 2002)

\begin{abstract}
Polyfunctionalized pyrrole $\mathbf{6}$ is synthesized in the ring transformation of $N$-hydroxy-3,5-dinitro4-pyridone 4 with enolate 2 derived from diethyl 3-oxogulutarate. The present reaction proceeds with $\mathrm{C}-\mathrm{N}$ transfer from 4 to 2 , which is hitherto unknown manner in similar reactions using dinitropyridone series.
\end{abstract}

Keywords: $N$-Hydroxydinitropyridone, ring transformation, polyfunctionalized pyrrole

\section{Introduction}

$\mathrm{N}$-Arylated (or $\mathrm{N}$-alkylated) 3,5-dinitro-4-pyridones 1 show dual reactivity to cause two kinds of ring transformations. In the reaction of $\mathbf{1}$ with sodium enolate anion $\mathbf{2 a}$, pyridone $\mathbf{1}$ behaves as the synthetic equivalent of $N$-substituted diformylamine to give 3,5-difunctionalized 4-pyridones 3. ${ }^{1}$ Another ring transformation is the displacement of the ring nitrogen with nucleophiles suchas acetoacetate $^{1}$ and primary amines. ${ }^{2,3}$ When hydroxylamine is used as a nucleophile, the ring nitrogen is similarly exchanged affording $N$-hydroxy-3,5-dinitro-4-pyridone 4. Furthermore, pyridone 4 is converted to synthetically useful salt of nitroisoxazolone $5^{4-6}$ on treatment with excess amounts of hydroxylamine. ${ }^{7}$ In the present reaction, the C2-C3-C4 moiety of pyridone 4 is built into isoxazolone $\mathbf{5}$, which has not been observed in reactions of $\mathbf{1}$ with other nucleophiles.

This result prompts us to study the ring transformation of $\mathbf{4}$ with bidentate enolate $\mathbf{2 a}$. As a result, we found an unusual and new ring transformation leading to polyfunctionalized pyrrole 6 . 


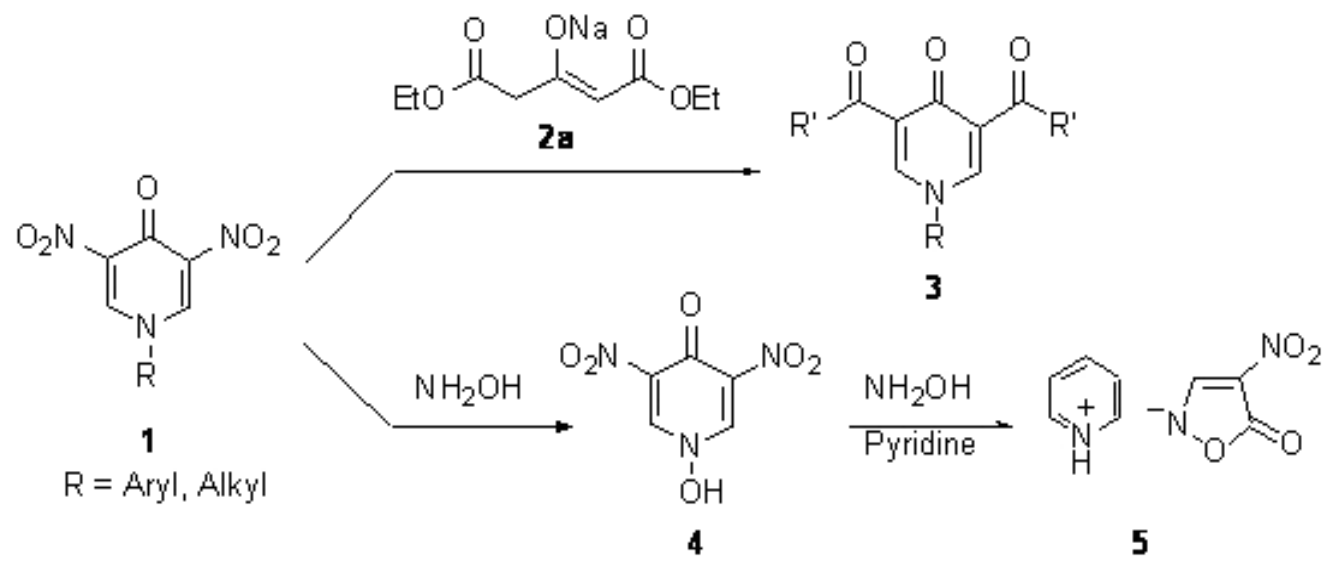

Scheme 1

\section{Results and Discussion}

In the reaction of pyridone $\mathbf{4}$ with sodium enolate 2a, a trace amount of crystalline product $\mathbf{6}$ is isolated in addition to usual ring transformed product, ${ }^{1} \mathrm{~N}$-hydroxy-3,5-bis(ethoxycarbonyl)-4pyridone. The observation of two unequivalent ethoxy signals in the ${ }^{1} \mathrm{H}$ NMR of $\mathbf{6}$ suggests that diester 2 acquires unsymmetrical framework. On the basis of spectral and analytical data, the structure of $\mathbf{6}$ is determined as 2,4-bis(ethoxycarbonyl)-3-hydroxypyrrole, which is finally confirmed by X-ray crystallography (Figure 1). Acetonitrile is found to be the suitable solvent, and heating is also necessary (Table 3). Using triethylammonium enolate $\mathbf{2 b}$ is effective to improve the yield of $\mathbf{6}$ up to $30 \%$ with easier experimental manipulations.

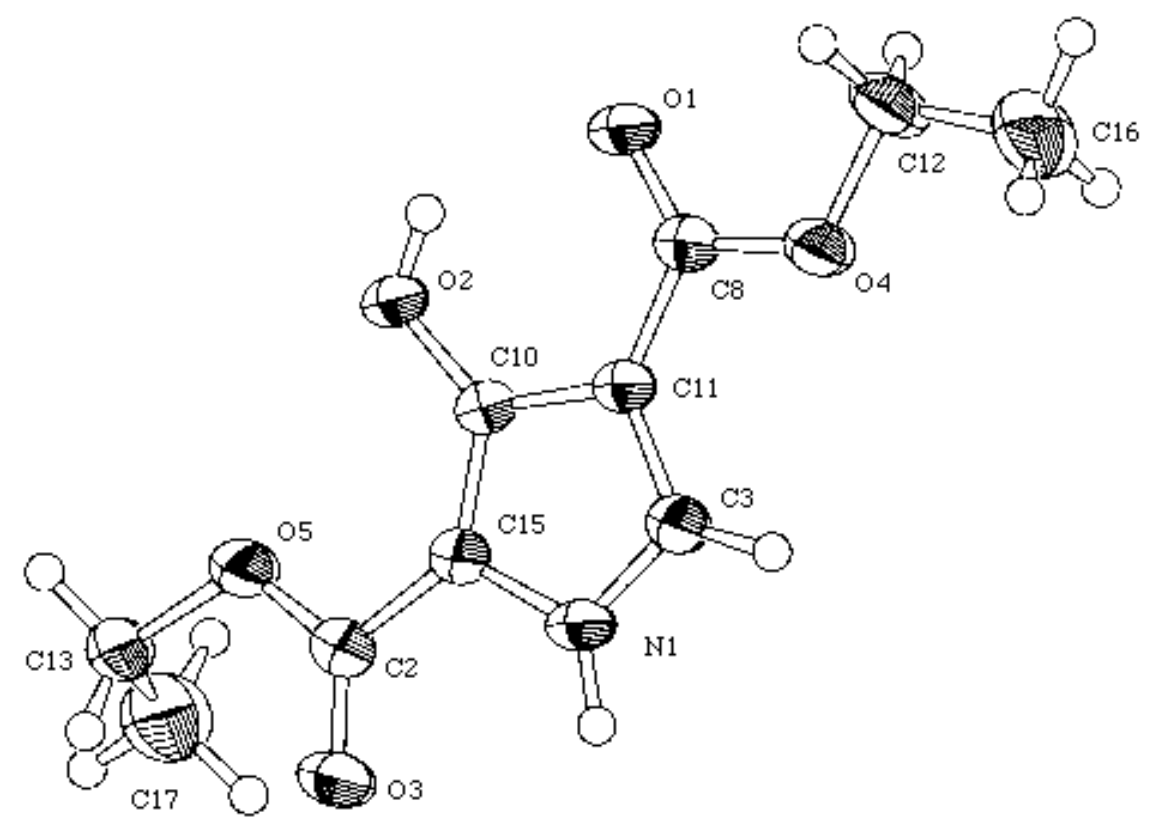

Figure 1 
Table 1. Intramolecular bond angles involving the nonhydrogen atoms

\begin{tabular}{llll}
\hline atom & atom & atom & angle \\
\hline $\mathrm{C}(8)$ & $\mathrm{O}(4)$ & $\mathrm{C}(12)$ & $116.0(2)$ \\
$\mathrm{C}(2)$ & $\mathrm{O}(5)$ & $\mathrm{C}(13)$ & $116.4(2)$ \\
$\mathrm{C}(3)$ & $\mathrm{N}(1)$ & $\mathrm{C}(15)$ & $110.2(2)$ \\
$\mathrm{O}(3)$ & $\mathrm{C}(2)$ & $\mathrm{O}(5)$ & $124.5(2)$ \\
$\mathrm{O}(3)$ & $\mathrm{C}(2)$ & $\mathrm{C}(15)$ & $123.7(2)$ \\
$\mathrm{O}(5)$ & $\mathrm{C}(2)$ & $\mathrm{C}(15)$ & $111.8(2)$ \\
$\mathrm{N}(1)$ & $\mathrm{C}(3)$ & $\mathrm{C}(11)$ & $108.8(2)$ \\
$\mathrm{O}(1)$ & $\mathrm{C}(8)$ & $\mathrm{O}(4)$ & $123.3(2)$ \\
$\mathrm{O}(1)$ & $\mathrm{C}(8)$ & $\mathrm{C}(11)$ & $122.7(2)$ \\
$\mathrm{O}(4)$ & $\mathrm{C}(8)$ & $\mathrm{C}(11)$ & $114.0(2)$ \\
$\mathrm{O}(2)$ & $\mathrm{C}(10)$ & $\mathrm{C}(11)$ & $126.4(2)$ \\
\hline
\end{tabular}

\begin{tabular}{lclc}
\hline \multicolumn{1}{c}{ atom } & atom & atom & angle \\
\hline $\mathrm{O}(2)$ & $\mathrm{C}(10)$ & $\mathrm{C}(15)$ & $125.7(2)$ \\
$\mathrm{C}(11)$ & $\mathrm{C}(10)$ & $\mathrm{C}(15)$ & $107.9(2)$ \\
$\mathrm{C}(3)$ & $\mathrm{C}(11)$ & $\mathrm{C}(8)$ & $130.1(2)$ \\
$\mathrm{C}(3)$ & $\mathrm{C}(11)$ & $\mathrm{C}(10)$ & $106.6(2)$ \\
$\mathrm{C}(8)$ & $\mathrm{C}(11)$ & $\mathrm{C}(10)$ & $123.3(2)$ \\
$\mathrm{O}(4)$ & $\mathrm{C}(12)$ & $\mathrm{C}(10)$ & $107.1(3)$ \\
$\mathrm{O}(5)$ & $\mathrm{C}(13)$ & $\mathrm{C}(17)$ & $111.3(3)$ \\
$\mathrm{N}(1)$ & $\mathrm{C}(15)$ & $\mathrm{C}(2)$ & $118.7(2)$ \\
$\mathrm{N}(1)$ & $\mathrm{C}(15)$ & $\mathrm{C}(10)$ & $106.6(2)$ \\
$\mathrm{C}(2)$ & $\mathrm{C}(15)$ & $\mathrm{C}(10)$ & $134.7(2)$ \\
\hline
\end{tabular}

Angles are in degrees. Estimated standard deviations in the least significant figure are given in parentheses.

Table 2. Intramolecular bond length involving the nonhydrogen atoms

\begin{tabular}{lll}
\hline atom & atom & distance \\
\hline $\mathrm{O}(1)$ & $\mathrm{C}(8)$ & $1.215(3)$ \\
$\mathrm{O}(2)$ & $\mathrm{C}(10)$ & $1.349(3)$ \\
$\mathrm{O}(3)$ & $\mathrm{C}(2)$ & $1.207(3)$ \\
$\mathrm{O}(4)$ & $\mathrm{C}(8)$ & $1.339(3)$ \\
$\mathrm{O}(4)$ & $\mathrm{C}(12)$ & $1.458(3)$ \\
$\mathrm{O}(5)$ & $\mathrm{C}(2)$ & $1.336(3)$ \\
$\mathrm{O}(5)$ & $\mathrm{C}(13)$ & $1.466(3)$ \\
$\mathrm{N}(1)$ & $\mathrm{C}(3)$ & $1.338(3)$ \\
\hline
\end{tabular}

\begin{tabular}{lcc}
\hline \multicolumn{1}{c}{ atom } & atom & distance \\
\hline $\mathrm{N}(1)$ & $\mathrm{C}(15)$ & $1.394(3)$ \\
$\mathrm{C}(2)$ & $\mathrm{C}(15)$ & $1.453(3)$ \\
$\mathrm{C}(3)$ & $\mathrm{C}(11)$ & $1.380(3)$ \\
$\mathrm{C}(8)$ & $\mathrm{C}(11)$ & $1.441(3)$ \\
$\mathrm{C}(10)$ & $\mathrm{C}(11)$ & $1.423(3)$ \\
$\mathrm{C}(10)$ & $\mathrm{C}(15)$ & $1.376(3)$ \\
$\mathrm{C}(12)$ & $\mathrm{C}(10)$ & $1.496(4)$ \\
$\mathrm{C}(13)$ & $\mathrm{C}(17)$ & $1.475(5)$ \\
\hline
\end{tabular}

Distances are in I. Estimated stand ard deviations in the least significant figure are given in parentheses.

Table 3. The effects of solvents and counter cations of enolate 2<smiles>O=c1c([N+](=O)[O-])cn(O)cc1[N+](=O)[O-]</smiles>

4

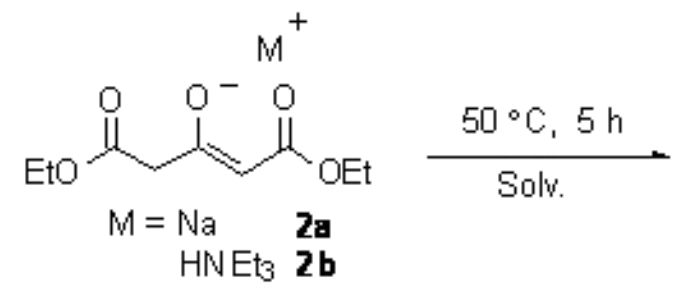

HNEt3 2b<smiles>CCOC(=O)c1c[nH]c(C(=O)OCC)c1O</smiles>

\begin{tabular}{cccc}
\hline run & Enolate & Solv. & Yield $/ \%$ \\
\hline 1 & $\mathbf{2 a}$ & Pyridine & 10 \\
2 & $\mathbf{2 a}$ & DMF & 10 \\
3 & $\mathbf{2 a}$ & MeCN & 18 \\
4 & $\mathbf{2 b}$ & MeCN & 30 \\
\hline
\end{tabular}


Pyridone $\mathbf{4}$ has an acidic hydroxy group enough forming ammonium salt $\mathbf{7}$ with amines, and whole salt $\mathbf{7}$ is returned to $\mathbf{4}$ under acidic conditions without forming any by-products. On the other hand, $O$-protected dinitropyridone 8 only affords complex mixture under the same conditions used for the reaction of $\mathbf{4}$. Taking these experimental facts into consideration, we suggest a plausible mechanism as illustrated in Scheme 2.<smiles>[NH3+][O-]</smiles>

7<smiles>COn1cc([N+](=O)[O-])c(=O)c([N+](=O)[O-])c1</smiles>

8

Figure 2

The acidic $N$-hydroxy group is considered to play an important role for causing unusual ring transformation. Initially formed salt 7' undergoes ring opening reaction leading to nitroso compound $\mathbf{9}$ prior to the attack of enolate $\mathbf{2}$ to $\mathbf{4}$ that is prevented by anionic property of the pyridone ring. After addition of enolate $\mathbf{2}$ to 9, regenerated enolate $\mathbf{1 0}$ constructs a five membered ring by intramolecular cyclization. The following aromatization of $\mathbf{1 1}$ furnishes pyrrole 6. Detailed study on this reaction (determination of the mechanism and application to other active methylene compounds) is in progress, and new results will be shown in due course.<smiles></smiles>

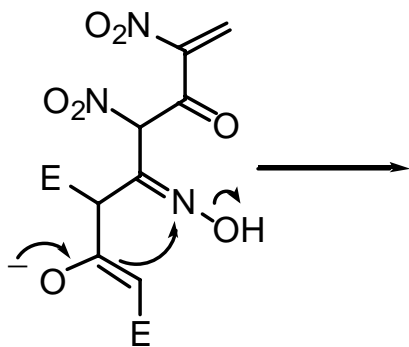

10<smiles>C=C(C(=O)C(N=O)=C(CC)CCF)C(=O)[N+](=O)[O-]</smiles>

2 (E = COOEt)
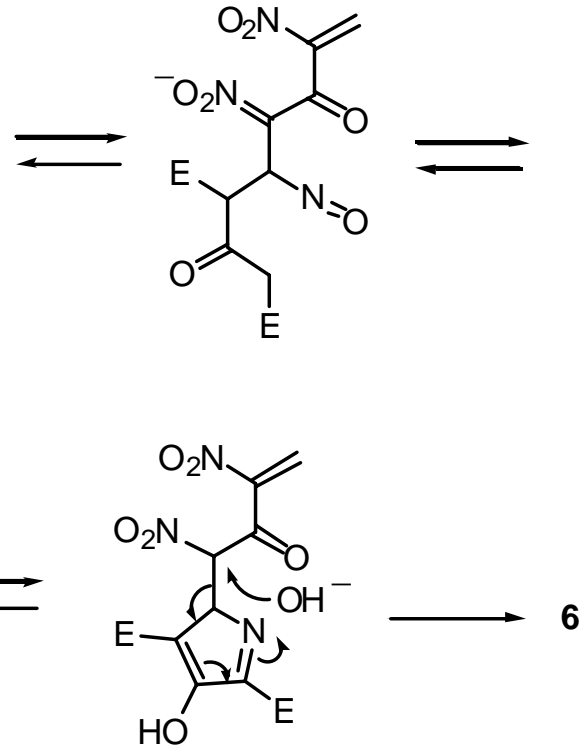

Scheme 2. A plausible mechanism. 


\section{Experimental Section}

General Procedures. Melting points (uncorrected) were determined on a Yanaco micromelting-points apparatus. ${ }^{1} \mathrm{H}$ NMR and ${ }^{13} \mathrm{C}$ NMR spectra were recorded on a Bruker DPX 400 spectrometer at $400 \mathrm{MHz}$ and at $100 \mathrm{MHz}$ with TMS as an internal standard. Coupling constants are given in $\mathrm{Hz}$ and without sign. The IR spectra were recorded on a Horiba FT-200 IR spectrometer. Elemental analyses were performed using a Yanaco MT-3 CHN corder.

Materials. All the reagents were commercially available and used as received. Solvents were dried and distilled according to usual methods.

2,4-Bis(ethoxycarbonyl)-3-hydroxypyrrole (6). The sodium enolate 2a was prepared from diethyl 3-oxoglutarate $(1.09 \mathrm{~mL}, 6.0 \mathrm{mmol})$ and NaOEt $(6.0 \mathrm{mmol})$ in EtOH $(20 \mathrm{~mL})$. After removal of $\mathrm{EtOH}$, the resultant enolate was dissolved in pyridine $(20 \mathrm{~mL})$. A half amount of the solution (10 mL) was added to a solution of pyridone 4 (402 mg, $2.0 \mathrm{mmol})$ in pyridine (40 mL) on an ice bath, and the mixture was heated at $50{ }^{\circ} \mathrm{C}$ for 5 hours. The reaction mixture was quenched with $1 \mathrm{M} \mathrm{HCl}$ (3 mL, $3.0 \mathrm{mmol}$ ), and concentrated under reduced pressure. The residual reddish oil was treated with column chromatography on silica gel to afford pyrrole $\mathbf{6}$ as yellow solid eluted with $\mathrm{CHCl}_{3}$. Further purification was performed with recrystallization from a mixed solvent of PhH and hexane (1 / 1) to give pyrrole 6 as yellow plates, yield $46 \mathrm{mg}$ (10\%), mp 129-130 ${ }^{\circ} \mathrm{C}$; IR (Nujol) v 3345, 3234, 1684, $1655 \mathrm{~cm}^{-1} ;{ }^{1} \mathrm{H}$ NMR $\left(\mathrm{CDCl}_{3}\right) \delta 1.36(\mathrm{t}, J=7.1$, 3H), 1.46 (t, $J=7.1,3 \mathrm{H}), 4.39$ (q, $J=7.1,2 \mathrm{H}), 4.41$ (q, $J=7.1,2 \mathrm{H}), 7.23$ (d, $J=4.0,1 \mathrm{H}), 8.4-$ 8.6 (br, 1H), 8.9-9.1 (br, 1H); ${ }^{13} \mathrm{C} \mathrm{NMR}\left(\mathrm{CDCl}_{3}\right) \delta 14.1(\mathrm{q}), 14.4(\mathrm{q}), 60.7(\mathrm{t}), 60.8(\mathrm{t}), 104.1(\mathrm{~s})$, 106.7 (s), 124.4,(d) 151.6 (s), 161.4 (s), 165.9 (s). Anal. Calcd. for $\mathrm{C}_{10} \mathrm{H}_{13} \mathrm{NO}_{5}$ : C, 52.86; $\mathrm{H}$, 5.77; N, 6.16. Found: C, 52.96; H, 5.88; N, 6.28.

Crystal data for pyrrole 6. $\mathrm{C}_{10} \mathrm{H}_{13} \mathrm{NO}_{5}, M=227.22$, monoclinic, space group $\mathrm{C} 2 / \mathrm{c}, a=$ 24.264(3) $\AA, b=7.313(4) \AA, c=14.636(3) \AA, \beta=122.779(8){ }^{\circ}, \mathrm{V}=2183(1) \AA^{3}, D=$ $1.382 \mathrm{~g} / \mathrm{cm}^{3}, Z=8, \mathrm{~F}(000)=960.00, \mu=1.12 \mathrm{~cm}^{-1}$. A dark yellow crystal of dimensions $0.30 \mathrm{x}$ $0.30 \times 0.30 \mathrm{~mm}$ was sealed in a glass capillary and used for measurement at $293 \mathrm{~K}$ on a Rigaku AFC7R four-circle diffractometer employing graphite monochromated MoK $\alpha$ radiation $(\lambda=$ $0.71069 \AA$ ) using the $\omega / 2 \theta$ scan technique. The 2519 unique reflections were corrected for Lorentz and polarization effects. The structure was solved by direct methods (SIR 88). The final full-matrix least squares refinement, based on $F$ using 1396 reflections $(I>3.00 \sigma(I))$ and 197 parameters, converged with $R=0.041$ and $R w=0.037$.

Reaction using triethylammonium enolate $2 \mathbf{b}$. To a solution of pyridone $\mathbf{4}$ (402 $\mathrm{mg}, 2.0 \mathrm{mmol}$ ) in MeCN (40 mL), were added diethyl 3-oxoglutarate $(0.54 \mathrm{~mL}, 3.0 \mathrm{mmol})$ and $\mathrm{NEt}_{3}(0.42 \mathrm{~mL}$, $3.0 \mathrm{mmol}$ ) at room temperature. After heating of the mixture at $50{ }^{\circ} \mathrm{C}$ for 5 hours, solvent was removed under reduced pressure. The residual oil was treated with column chromatography on silica gel to give crude pyrrole $\mathbf{6}$ as yellow solid eluted with chloroform. Recrystallization from a mixed solvent of $\mathrm{PhH}$ and hexane (1 / 1) afforded pure pyrrole 6 as yellow plates, yield $138 \mathrm{mg}$ (30\%). 
1-Methoxy-3,5-dinitro-4-pyridone (8). To a solution of $\mathrm{KOH}$ (112 mg, $2.0 \mathrm{mmol}$ ) in $\mathrm{MeOH}$ $(10 \mathrm{~mL})$, were added 1-hydroxypyridone 4 (402 mg, $2.0 \mathrm{mmol})$ and $\mathrm{MeI}(0.31 \mathrm{~mL}, 5.0 \mathrm{mmol})$, and the mixture was heated under reflux for 1 day. After removal of solvent, the residue was extracted with EtOAc (30 mL x 3), dried over $\mathrm{MgSO}_{4}$ and the organic layer was evaporated. Recrystallization of the residual solid gave $O$-methylated pyridone $\mathbf{8}$ as dark yellow plates, yield 73 mg (16 \%), mp 196-198 ${ }^{\circ} \mathrm{C}$; IR (Nujol) v 1668, 1510, 1349, $1295 \mathrm{~cm}^{-1}$; ${ }^{1} \mathrm{H}$ NMR (DMSO-d 6 ) $\delta 4.24$ (s, 3H), 9.62 (s, 2H); ${ }^{13} \mathrm{C}$ NMR (DMSO-d $\left.{ }_{6}\right) \delta 68.2$ (q), 140.3 (s), 140.5 (d), 158.7 (s). Anal. Calcd. for $\mathrm{C}_{6} \mathrm{H}_{5} \mathrm{~N}_{3} \mathrm{O}_{6}$ : C, 33.50; H, 2.34; N, 19.53. Found: C, 33.79; H, 2.34; N, 19.50.

\section{References}

1. Matsumura, E.; Ariga, M.; Tohda, Y. Bull. Chem. Soc. Jpn. 1980, 53, 2891.

2. Matsumura, E.; Kobayashi, H.; Nishikawa, T.; Ariga, M.; Tohda, Y.; Kawashima, T. Bull. Chem. Soc. Jpn. 1984, 57, 1961.

3. Matsumura, E.; Ariga, M.; Tohda, Y.; Kawashima, T. Tetrahedron Lett. 1981, 22, 757.

4. Nishiwaki, N.; Nogami, T.; Kawamura, T.; Asaka, N.; Tohda, Y.; Ariga, M. J. Org. Chem. 1999, 64, 6476.

5. Nishiwaki, N.; Nogami, T.; Tanaka, C.; Nakashima, F.; Inoue, Y.; Asaka, N.; Tohda, Y.; Ariga, M. J. Org. Chem. 1999, 64, 2160.

6. Nishiwaki, N.; Takada, Y.; Inoue, Y.; Tohda, Y.; Ariga, M. J. Heterocycl. Chem. 1995, 32, 473.

7. Ariga, M.; Tohda, Y.; Nakashima, H.; Tani, K.; Mori, Y.; Matsumura, E. Bull. Chem. Soc. Jpn. 1991, 64, 3544. 